\title{
Textile shelters for archaeological or heritage areas: design references
}

\author{
M. Mollaert ${ }^{1}$, L. De Laet ${ }^{1}$, A. Verdonck ${ }^{1}$, S. Lombardi ${ }^{2}$, \\ P. Beccarelli ${ }^{3}$ \& A. Zanelli ${ }^{3}$ \\ ${ }^{I}$ Department of Architectural Engineering, \\ Vrije Universiteit Brussel, Belgium \\ ${ }^{2}$ Canobbio, $S p A$, Italy \\ ${ }^{3}$ Politecnico di Milano, Building Environment Science \\ and Technology Department, Italy
}

\begin{abstract}
The paper gives a short summary of the properties of tensile surface structures made out of technical textiles. Tensile surface coverings can protect archaeological or heritage areas against deterioration and revalue these sites for visitors. Covering systems have to combine several preservation requirements like protection from environmental and pollution load, low maintenance, compatibility of new materials, reversibility, ease of disassembly, reusability, adaptability and flexibility. Textile lightweight structures present a great number of advantages like easy mounting, natural aeration, elegant design and filtered natural day lighting.

Building on archaeological or heritage areas is a delicate task. Architects have to compare alternative approaches and find solutions appropriate for the situation under consideration. The discussion on built shelters, presented together with the underlying concepts, the performance, the used primary structure and the chosen coated fabric can support design decisions in future.

A recent research activity has been started in Sardinia (Italy). The aim is to analyse technical aspects and to clarify which solutions really serve to protect while others contribute to further damage. Prototypes have been built in order to evaluate the behaviour of some innovative textile materials in comparison with traditional ones.
\end{abstract}

Keywords: tensile surface structures, covering of archaeological sites. 


\section{Introduction}

The paper presents the possibilities of textile architecture. The potential is clarified in the context of archaeological or heritage areas.

The references are limited, possibly because of the very specific requirements with respect to archaeological or heritage sites on the one hand, and the fact that the experts involved in conservation are not aware of the recent evolution in lightweight structures.

Existing references are discussed. They illustrate the variety and specificity of the corresponding designs. Comments from the point of view of textile architecture with respect to these applications are given. The conservation and exploitation requirements have to match with the concept of the architect in the aim to preserve and assure cultural valorisation.

\section{Textile architecture}

Textile architecture projects, also called 'tensile surface structures' or 'membrane structures' are constituted of a thin pre-tensioned membrane as covering element and can provide wide span enclosures. These textile architecture projects can be classified according to their appearance (open, enclosed, convertible structures) or according to their purpose (covering, internal use or attached spaces) (Figure 1). The membrane structures can be easily set up and dismantled (like a circus tent) and require minimal supporting elements. Structurally, a pneumatic system or a tensioned skin supported by a primary structure (skeleton) can be used.

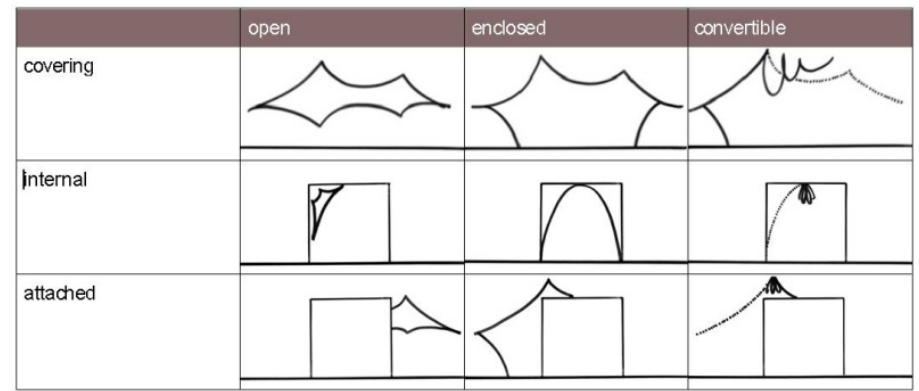

Figure 1: $\quad$ Classification of tensile surface structures (Forster, [1]).

Dependent on the technical textile used, different levels of protection, ranging from sun shading to a protection against wind, rain, snow or high variations in temperature can be achieved. Also, the level of translucency (from highly translucent with good overall levels of natural daylight to opaque) depends on the material used and can be chosen by the designer or customer, just like the insulation level (applying a single thin layer or highly insulated multi-layers). 
A variety of geometries and configurations are possible. The membrane structures can be temporary or for permanent use (the lifespan of the technical fabrics is $\sim 30$ years), can be engineered as an adaptable or retractable structure, can be constituted of prefabricated elements etc.

The technology has also its limits and disadvantages: special attention has to go to protection against vandalism, fire proof materials, appropriate anchorage and budget friendly solutions.

\section{Built examples of protective shelters}

\subsection{Temporary cover for the temple of Apollo Epikourios, Bassae - 1987}

'Bassae is an archaeological site in the north-eastern part of Messinia Prefecture that was a part of Arcadia in ancient times. It is famous for the well-preserved mid- to late- $5^{\text {th }}$ century BC Temple of Apollo Epicurius. Although this temple is geographically remote from major polities of ancient Greece, it is one of the most studied ancient Greek temples because of its multitude of unusual features. Bassae was the first Greek site to be inscribed on the World Heritage List (1986). A long list of superlatives could be used to describe the site and the temple itself' [2].

The entire temple has been shrouded in a large canopy since 1987 (Figure 3); an effort to halt the disintegration of the limestone structure and the slow subsidence of its foundation while restoration is completed.

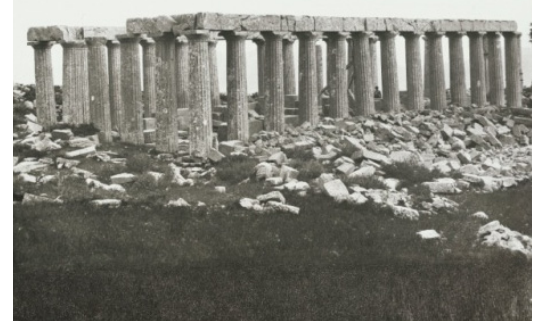

Figure 2: $\quad$ Temple of Apollo Epikourios (Bryn Mawr College lantern slide).

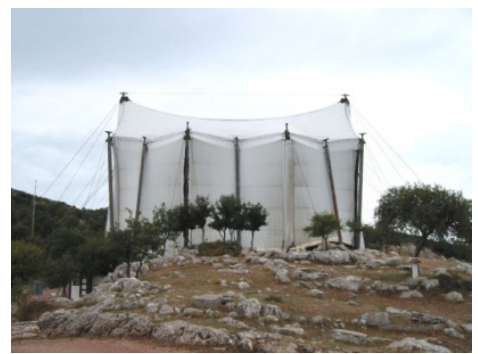

(a)

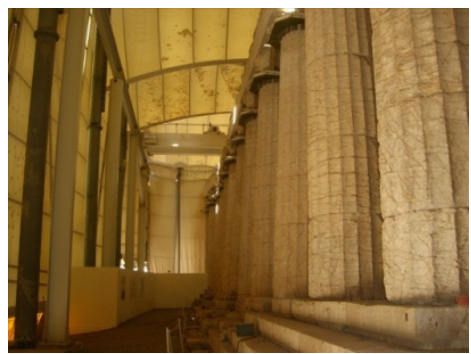

(b)

Figure 3: $\quad$ Textile cover (Canobbio): (a) outside view, (b) inside view. 
This enclosed covering, although planned to be temporary, has been installed for 24 years. All this time it hides the magnificent temple. The covering could be made convertible (opening the side walls) or transparent by replacing some of the wall panels with clear but reflective foils.

\subsection{Roof over archaeological excavation sites on Pianosa - 1990 (Schock [3, 4])}

The excavation sites of the Roman villa Agrippa on the island of Pianosa in the Tyrrhenian Sea south of Elba are protected by a modular membrane roof with a space truss as primary structure (Figure 4).

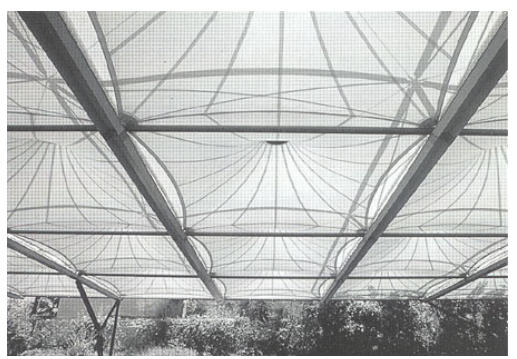

(a)

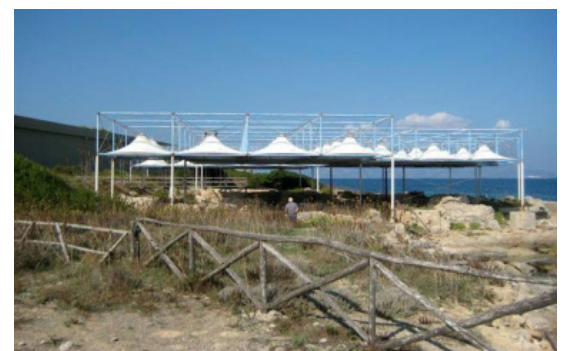

(b)

Figure 4: Tensile roof on the excavation site: (a) in 1990, (b) current situation.

The open covering has the function of protecting the archaeological findings from the weather and simultaneously limiting the vegetation growth within the excavation site.

The following design criteria were taken into account: (i) the application of a modular structure made from small and lightweight elements, to ease the sometimes difficult access to the excavation site, (ii) allow short-term adjustments during the survey of the foundations by the redistribution of the supports of the space truss, (iii) no or limited interference with the excavations requiring only small foundations and (iv) a certain translucence was desired, to avoid too strong shadows, which would have inhibited the excavations. A high translucence had to be avoided to protect the archaeological findings from UVradiation and to avoid glare.

The situation of the Roman villa of Agrippa on Pianosa nowadays reflects that of the island: a territory in disarmament.

The only present 'modern work' is the protecting tensile roof, which currently has an ugly aesthetic appearance. The main cause is the absolute lack of resources.

A small financial effort will be made in order to remove the rust of the frame of the roof and to clean up the building in sight of the next tourist season.

This case illustrates the need for budget and basic maintenance. 


\subsection{Kalavasos-Tenta, Cyprus - 1994 ([5])}

The archaeological site of Kalavasos lies to the west of the Vasilikos river valley, about $45 \mathrm{~km}$ south of Lefkosia. In the beginning of the nineties a pyramidal construction in wood and textile was constructed over the archaeological site to improve its protection (Figure 5).

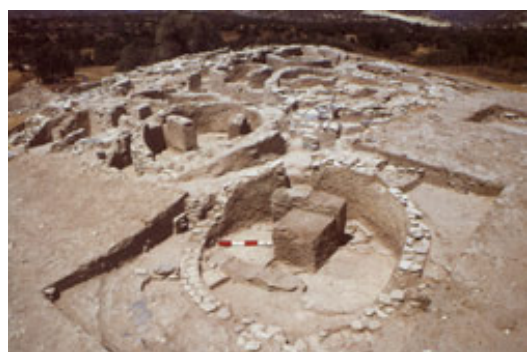

(a)

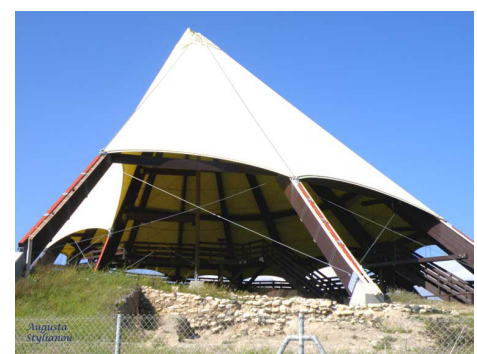

(b)

Figure 5: Kalavasos-Tenta: (a) buildings during excavation, (b) the canopy.

The tent-like structure, $16 \mathrm{~m}$ high, is formed by a frame of 14 wooden beams rising from concrete bedding and joined at the top by a metal ring. A PVCcoated polyester fabric covers the frame. An interior walkway is suspended from the beams to allow visitors to observe the site from above. The canopy is a 'land mark' if one travels from east to west along the motorway.

The open light translucent covering protects the archaeological site as well as the visitors. The tent-like structure in this case is a pre-tensioned skin supported by a prominent pyramidal frame structure.

\subsection{Capo Soprano Greek walls, Sicily - 2008 ([6, 7], Lombardi and Canobbio [8])}

The Capo Soprano Greek Walls were uncovered in 1952 from the sand-dunes that had swamped and then preserved them. They date from Timoleon's revival of the city in $338 \mathrm{BC}$ as it fell to Agathocles in $311 \mathrm{BC}$.

At the Istituto Centrale del Restauro, architect Franco Minissi (1919-96), was trying to dialogue between modern architecture and historical pre-existence and he introduced innovating technologies and materials in the field of restoration.

Franco Minissi devised a protection for the Greek walls at Capo Soprano: by means of tempered glass plates he secured the raw clay bricks in the upper part, very windward and sunned (Figure 6(a)). Another function of the plates, connected with metallic elements, was to practice a pressure on the bricks for their containment. The coverage prevented every possible infiltration of water but it has been removed a few years later, because considered too modern.

The process of disaggregation started after the dismantlement of the rain protection. It has been tried once again to protect the walls with a temporary roof 
supported by scaffolding (Figure 6(b)). The result was a shabby structure with a terrible visible impact on the walls.

This is the reason that led the Sicily cultural heritage to search for a new suitable covering system consisting of an open structure covered with a tensioned PTFE coated fibreglass fabric (Figure 7). The primary structure is an arch shaped portal frame made of COR-TEN steel positioned every $15 \mathrm{~m}$.

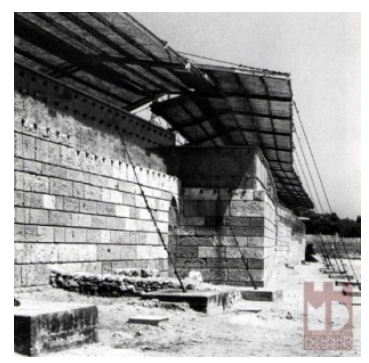

(a)

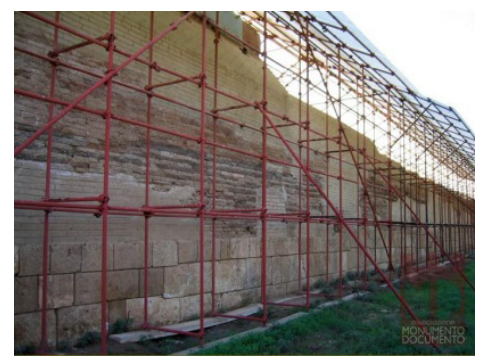

(b)

Figure 6: Capo Soprano Greek Walls: (a) first cover, (b) second shelter.

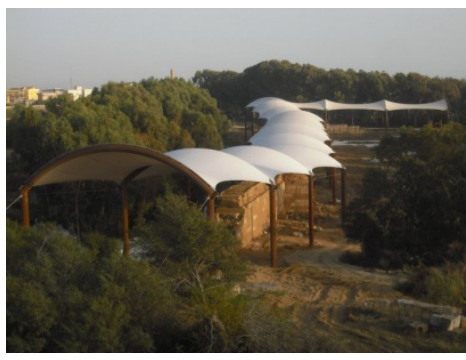

(a)

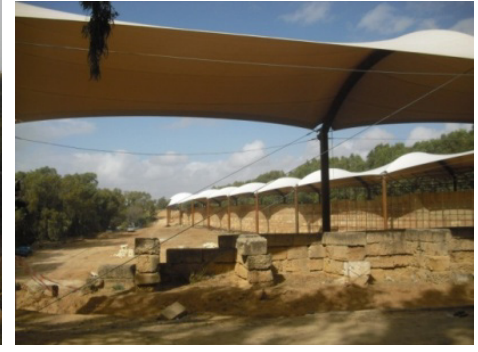

(b)

Figure 7: (a) and (b) Translucent surfaces covering the Capo Soprano Greek Walls.

The open covering consists of small repetitive units, floating above the massive walls. This covering is indeed lightweight, especially in terms of visible impact. Due to its building simplicity and symmetry, it offers to the visitors a similar visible identity on both sides of the walls. This solution preserves an appropriate micro-climate near the walls and it is at the same time secure, reversible, fire resistant, UV-resistant and easy to maintain.

\subsection{Hagar Qim and Mnajdra Temples, Malta - 2008 ([7], Lombardi and Canobbio [8-10])}

The Megalithic buildings represent the beginning of a magnificent expression of religion. They have been built between 3600 and $2500 \mathrm{BC}$. The astronomic alignment, which predicts the first day of the four seasons was firstly shown in the Mnajdra Temple. 
The philosophy behind the installation of protective shelters at Hagar Qim and Mnajdra (Figure 8) is to significantly retard the main external causes of deterioration, while researching further to consolidate the temple structures and restore some of their resilience to the elements. This kind of shelter is a low-risk intervention, fast and reversible.

The footprint of each protective shelter, as well as the anchor points of the tent structure, have been adapted to the topography of the respective sites, as well as to the different equinox and view axes of each temple (Figure 9).

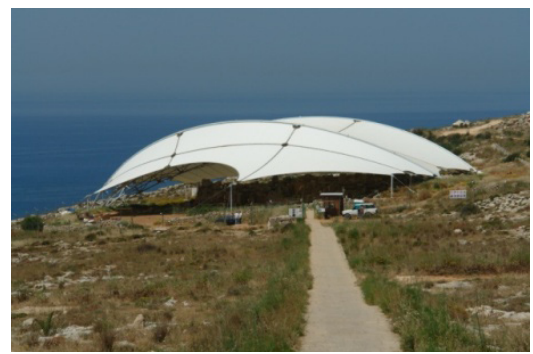

(a)

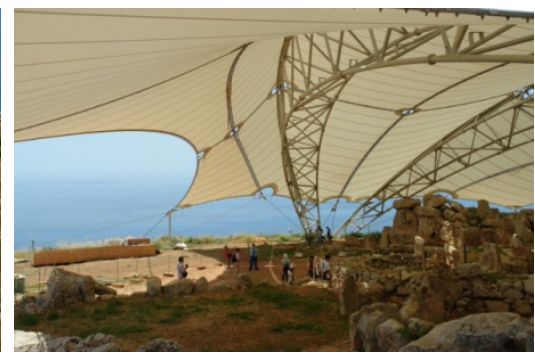

(b)

Figure 8: Textile cover of the Mnajdra Temple: (a) outside view, (b) inside view.

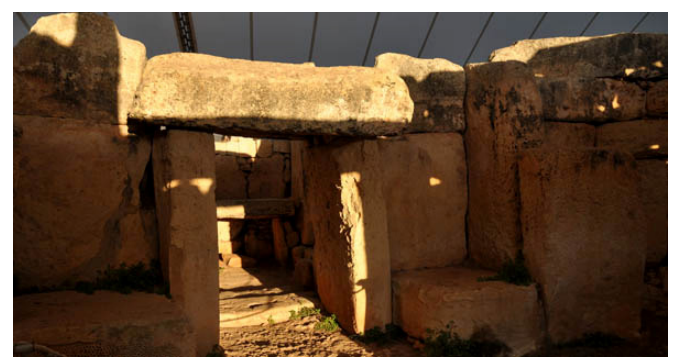

Figure 9: $\quad$ Mnajdra's winter solstice.

The protective shelters are in natural white textile membrane (PTFE fibreglass fabric) and matt gray steel support structure and tensioning elements.

The membrane filters the natural daylight penetrating to the interior down to 10 to $15 \%$ of the original intensity. The megalithic sites can still be appreciated under natural light.

The open coverings are arch supported; doubly curved large free span shelters intended to be temporary. 


\subsection{Cutty Sark, London - 2009 [11]}

The Cutty Sark Trust was in the middle of a major conservation project when a fire destroyed much of the ship. Additional fundraising was required to assure that the ship could be re-opened to the public in November 2009.

Designed by Bakoko's Alastair Townsend, the Cutty Sark Pavilion (Figure 10(a)) was built for a temporary exhibit of the famous historic ship. The cutting-edge visitor centre was built within a restricted budget and a tight construction program of only 6 months from design to completion.

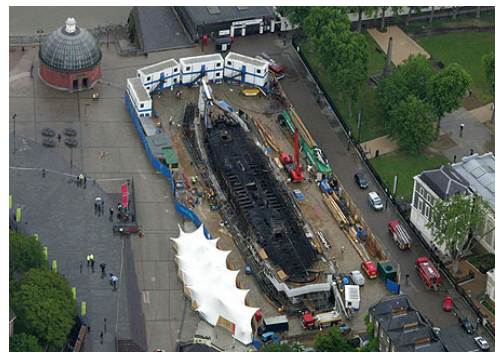

(a)

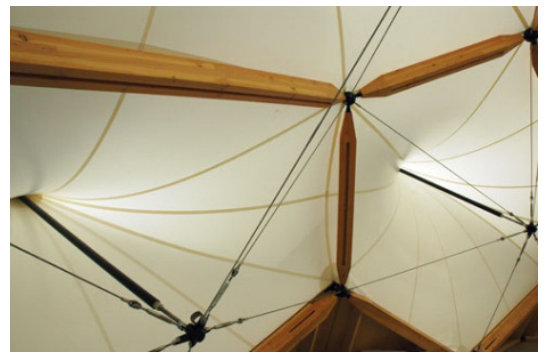

(b)

Figure 10: Pavilion at the Cutty Sark site: (a) outside view, (b) inside view [11].

The structure (Figure 10(b)) comprises of a PVC-coated polyester fabric supported by structural timber components, evocative of sails, masts and rigging of the majestic sailing ship.

Whilst the Cutty Sark conservation and structural works are being carried out, this enclosed covering will maintain the public's interest in the ship with an exhibition and the opportunity to view the on-going works.

\section{In depth research on protective textile shelters}

One of the important aspects to consider is that an incorrect design can contribute to an increase in damage rather than protection of the archaeological or heritage areas.

If the shelter's orientation does not afford adequate protection from direct solar irradiation or when the cover is opaque to infrared radiation and the heat radiation emitted by the ruins remains trapped underneath the shelter, the surface temperature of the protected materials can highly vary.

If the shape of the shelter prevents ventilation, humid air will induce condensation on cold surfaces during cooling, which will deteriorate the ruins, the metallic structures etc.

Another significant source of damage is the collection of rainwater from the shelter when drainage of rainwater has not been considered properly. The rainwater can damage the findings, also when it flows through the ruins. 
Few lightweight tensile surface structures have been built as protective shelters for archaeological or heritage areas. The performance of the technical textile materials needs to be investigated as well as the methodology to assure the quality of the solution in the specific context.

\subsection{Su Monte archaeological area, Sardinia (Beccarelli [12])}

The "Su Monte" archaeological ruins are located near the Sorradile village, at the very heart of Sardinia. The area is placed in correspondence with the southeastern bank of the artificial Lake Omodeo realised during the 1930's.

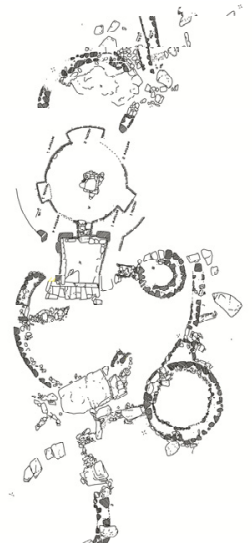

(a)

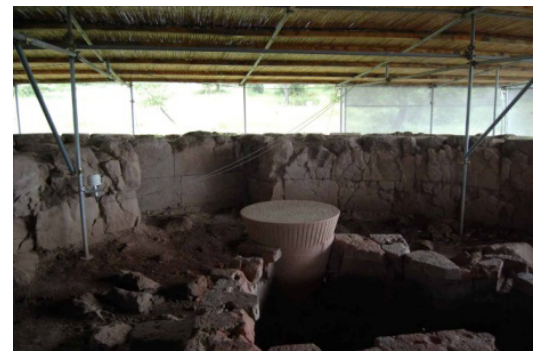

(b)

Figure 11: (a) and (b) Su Monte archaeological site.

The ruins are that of a "Nuraghe" religious settlement, made up by two-three courses of trachyte blocks, dating back to the end of $12^{\text {th }}$ century BC. The complex is composed of an elliptic fence of $100 \mathrm{~m} \times 60 \mathrm{~m}$. Inside the fence there is a group of buildings, the main being a circular temple with a trapezoidal entrance hall.

Following excavation of the site, the structures were restored between 1998 and 2003. In 2006, in order to reduce the deterioration and prevent uncontrolled growth of vegetation, the National Trust created a provisional shelter and fenced off the site to prevent the encroachment of wildlife.

In 2007, the main building underwent restoration. The surface of the stones had been eroding due to weathering, thermal effect, moisture, along with a huge and frequent variation in relative humidity.

The Su Monte Archaeological Area has been selected for the validation of a novel approach to the design of lightweight shelters (Figure 11). After the preliminary monitoring of the site microclimate and surface temperature, carried out between 2007 and 2008, two prototypes were tested in-situ in order to investigate the thermal response of membrane materials.

For the experimental setup, the prototypes were designed as simple tent structures using an existing supporting frame, made from scaffolding tubes 
(Figure 12). The design focused on a reduction in assembly costs maximising in terms of protection performance through a multi-layer roofing system (sacrificing a correct tensioning procedure). However, the structural and formal potentials of tensioned fabrics should be considered in future developments in order to maximise the benefits in terms of stability and wind protection.

The results of the experiments (Figure 13) showed that the irradiation coming through the overlapped PVC-Polyester and shading layers was small and almost the same as the amount passing through the reed ceiling of the existing shelter.

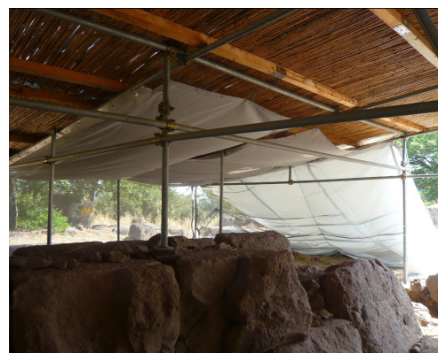

(a)

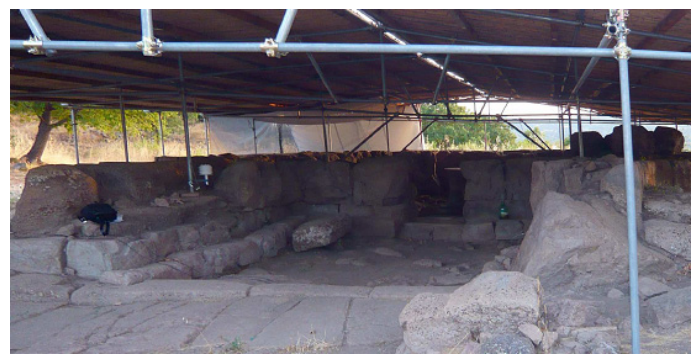

(b)

Figure 12: (a) and (b) Experimental set-up for measuring shading properties.

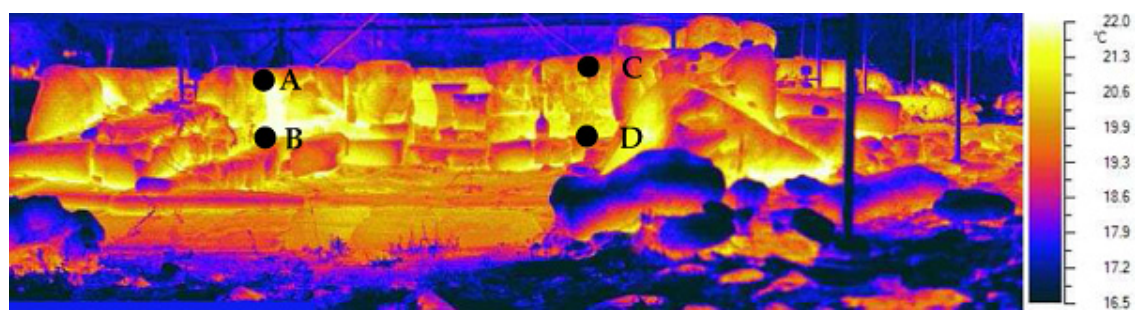

Figure 13: Evaluating the temperatures with infrared thermographic survey.

The relative humidity proved to be a critical aspect due to the proximity of the Lake Omodeo. At sunset the air temperature sharply decreases and condensation occurs, starting on the coldest surfaces. It was observed that on horizontal surfaces the liquid water remained for a long time. On these surfaces the presence of the water caused the crystallised salts to dissolve and consequently the absorption of the salt solution into the surface. The surfaces, being exposed to rapid variations in temperature and relative humidity, become damaged by means of cracks and exfoliation. Adjustable well-placed openings in the covering could assure the required ventilation.

Comparing the costs and the advantages of protection by fabric shelters, the study concludes that fabric shelters are highly competitive and a valid alternative to traditional ones, guaranteeing the same protection from solar irradiation. 


\subsection{Methodology}

Based on the state of the art study and the lack of fully documented reference projects, it became clear that a design strategy for tensile surface coverings of archaeological or heritage areas has to be developed. Different aspects have to be considered for existing as well as for future projects.

Is the temporary covering useful? Which criteria have to be satisfied (kind of protection, aesthetic requirements, use, maintenance, financial implications...).

How to choose between the possible concepts (decisions based on expertise)? Can design and realisation be finalised in the given time frame? Does the built protection have the postulated qualities (technically and with regard to the development of the site)?

Accurate coverings or shelters must satisfy a number of diverse criteria: they need to offer the required protection (from climatic conditions, vandalism, pollution...), evacuate rainwater correctly, be open or closed, temporary or durably, depending on the foreseen use, assure internal comfort by passive or active control, fit in the surroundings, be respectful to the historical context, be low in maintenance, aesthetically justified, offer a worthy (even if temporary) architectural answer and support the cultural interpretation of the site.

Case studies need to be documented with regard to the value of the site, the problems of decline, the required interventions, the function of the temporary covering, the maintenance of the site and the overall evaluation by means of objective measurements and subjective factors. Indicators must be established to be able to quantify the analysis. The methodology should be established by a multi-disciplinary team.

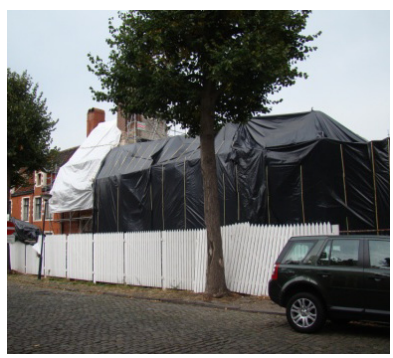

(a)

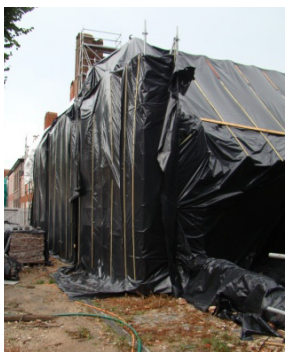

(b)

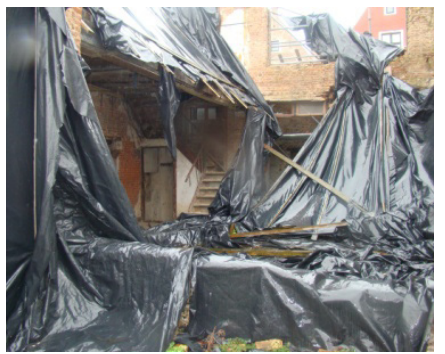

(c)

Figure 14: Convent ter eecken: (a) and (b) wrapped in foil, (c) after one winter.

The situation of some heritage sites (Figure 14) illustrates the need for proper in-time solutions. Wrapping a classified building in black plastic foil is not a valuable option: the quality of the protection is poor and inadequate. 


\section{Conclusions}

A brief state of the art has been presented.

Tensile surface structures offer several advantages such as high flexibility, low or aesthetical visual impact, natural shapes, modularity, suitability for any geometry, reusability, light supporting structure, easy transportation, low maintenance requirements and fast installation or dismantling, but all these have to be checked with respect to the criteria for the archaeological or heritage site under consideration. Projects can vary according to the design brief and creativity can steer a wide range of possible solutions for frames, forms and lightness.

To support the decisions during the design process, the partners in this process need well-documented case studies as references and design strategies based on the multi-disciplinary expertise. A first final study work starts to set up an initial scheme.

\section{References}

[1] Forster B., Mollaert M. (eds.), European Design Guide for Tensile Surface Structures, TensiNet, Brussels, 2004.

[2] http://en.wikipedia.org/wiki/Bassae, 2011

[3] Schock H.-J., Soft Shells: Design and Technology of Tensile Architecture Birkhäuser, 1997, ISBN 3-7643-5450-X

[4] http://iltirreno.gelocal.it/piombino/cronaca/2010/11/28/news/la-villa-diagrippa-in-abbandono-2846992, 2011

[5] http://www.kalavasos.org/english/arxaio xoroi tenta.shtm, 2011

[6] http://www.unipa.it/monumentodocumento/villadelcasale/mura capo soprano.html, 2011

[7] www.canobbio.com, 2011

[8] Lombardi S., Canobbio R., Covering for archeological sites (few examples), Proceedings TensiNet Symposium, Sofia, pp. 339-349, 2010, ISBN - 978-90-9025666-5

[9] http://gozonews.com/5910/shelter-project-at-hagar-qim-mnajdra-templeson-track/, 2011

[10] http://www.maltainsideout.com/8319/winter-solstice-at-mnajdra-temples/, 2011

[11] www.youmeheshe.com, 2011

[12] Beccarelli P., Romoli E., Rosina E., Zanelli A. (2010), Textile shelters for archaeological areas: a change in the preservation of Cultural Heritage, Proceedings TensiNet Symposium, Sofia, pp. 165-173, ISBN - 978-909025666-5

[13] Bogner-Balz H., Zanelli A. (eds), Ephemeral Architecture. Time and Textiles, Proceedings of Tensinet Symposium 2007, 16-18 April 2007, Politecnico di Milano, Clup, Milano, 2007. 